\title{
Simulation of the Tracer Diffusion, Bulk Ordering, and Surface Reordering in F.C.C. Structures by Kinetic Mean-Field Method
}

\author{
V. M. Bezpalchuk*, R. Kozubski ${ }^{\ddagger}$, and A. M. Gusak* \\ "Bohdan Khmelnytsky National University of Cherkasy, \\ 81 Shevchenko Blvd., \\ UA-18031 Cherkasy, Ukraine \\ ${ }^{\star}$ M. Smoluchowski Institute of Physics, Jagiellonian University in Krakow, \\ Lojasiewicza 11, \\ PL-30-348 Krakow, Poland
}

Tracer diffusion and 'chemical' (atomic) ordering processes in two facecentred cubic (f.c.c.) binary systems mimicking $\mathrm{Ni}_{3} \mathrm{Al}$ and $\mathrm{FePt}$ were simulated by means of the kinetic mean-field (KMF) method originally proposed by G. Martin in 1990. The systems simulated within the present work were modelled with fixed pair-interaction parameters and saddlepoint energies adopted earlier via the comparison of Monte Carlo method modelling and experimental data. In a simulation of tracer migration as well as ordering, the focus was attracted to comparison of activation energies rather than pre-exponential factors of kinetic coefficients. Generally, the mean-field models cannot properly take into account correlation effect that could be important for the tracer diffusion especially for the $B 2$ structures. However, at least for the f.c.c. structures, application of KMF to diffusion and ordering seems demonstrating very reasonable results qualitatively similar to those obtained in kinetic Monte Carlo (KMC) method and realistic experiments. Modelling of $\mathrm{Ni}$ - and Al-tracer diffusion in $\mathrm{Ni}_{3} \mathrm{Al}$ system shows higher diffusivity of $\mathrm{Ni}$ atoms as compared with $\mathrm{Al}$ ones that is attributed to easier intrasublattice diffusion channel for the $\mathrm{Ni}$ atoms in the $L 1_{2}-\mathrm{Ni}_{3} \mathrm{Al}$ superstructure. Also, the obtained activation energy for the tracer $\mathrm{Al}$ atoms is higher, and its value is closer to activation energy of ordering kinetics. Computer experiments for the ordering kinetics showed that, in contrast to exchange mechanism, $L 1_{2}$-type ordering kinetics is described via two relaxation times in case of the vacancy diffusion mechanism. Modelling of the discontinuous process of the surface-induced re-orientation of the monatomic Fe and $\mathrm{Pt}$ planes in thin FePt film was, in turn, a good test for the stochastic variant of the KMF (SKMF) method. The fact that implementation of the stochastic noise was 
needed to reproduce the process of a surface nucleation by KMF indicates the correctness of the method.

В роботі розглядається моделювання дифузії значених атомів і процесу «хемічного» (атомового) впорядкування в двох бінарних системах 3 гранецентрованою кубічною (ГЦК) структурою $\mathrm{Ni}_{3} \mathrm{Al}$ та $\mathrm{FePt}$ із використанням середньопольової кінетичної методи (KMF), запропонованої Ж. Мартаном у 1990 р. Для систем, що розглядаються в рамках даної роботи, використовувалися фіксовані значення парних енергій взаємодій та енергій сідлової точки, підібрані раніше шляхом порівняння моделювання за методою Монте-Карло й експериментальних даних. У моделюванні дифузії значених атомів, а також упорядкування їх основний акцент робиться на порівнянні енергій активації, а не передекспонентних множників кінетичних коефіцієнтів. В загальному випадку середньопольові моделі не можуть правильно враховувати кореляційний ефект, який може бути істотним для дифузії значених атомів, особливо для структур типу $B 2$. Проте, принаймні для ГЦК-структур, застосування KMF-методи до дифузії та упорядкування демонструє достатньо реалістичні результати, якісно схожі на ті, що одержуються 3 кінетичної методи Монте-Карло і в реальних експериментах. Моделювання дифузії значених атомів $\mathrm{Ni}$ i $\mathrm{Al}$ в системі $\mathrm{Ni}_{3} \mathrm{Al}$ показує швидшу дифузію атомів $\mathrm{Ni}$, ніж $\mathrm{Al}$, що пов'язано з легшою дифузією атомів $\mathrm{Ni}$ по власній підгратниці в надструктурі типу $L 1_{2}-\mathrm{Ni}_{3} \mathrm{Al}$. Також одержано вищу енергію активації для значених атомів $\mathrm{Al}$ та її близьке значення до енергії активації кінетики впорядкування. Комп'ютерні експерименти з кінетики впорядкування показали, що, на відміну від обмінного механізму, за вакансійного механізму дифузії кінетика впорядкування за типом $L 1_{2}$ описується двома часами релаксації. Моделювання переривчастого процесу приповерхневої переорієнтації моноатомових площин Fe i Pt у тонкій плівці FePt, у свою чергу, стало хорошим тестом для стохастичного варіянту KMF (SKMF). Той факт, що введення стохастичного шуму виявилося необхідним для відтворення процесу поверхневої нуклеації, може свідчити про коректність методи.

В работе рассматривается диффузия меченых атомов и процесс «химического" (атомного) упорядочения в двух бинарных системах с гранецентрированной кубической (ГЦК) структурой $\mathrm{Ni}_{3} \mathrm{Al}$ и $\mathrm{FePt}$ с использованием среднеполевого кинетического метода (KMF), предложенного Ж. Мартаном в 1990 г. Для указанных систем использовались фиксированные значения парных энергий взаимодействия и энергий седловой точки, подобранные ранее путём сравнения моделирования методом Монте-Карло и экспериментальных данных. В моделировании диффузии меченых атомов, а также упорядочения их основной акцент направлен на сравнение энергий активации, а не предэкспонентных множителей кинетических коэффициентов. В общем случае модели среднего поля не могут правильно учитывать корреляционный эффект, который может быть существенным для диффузии меченых атомов, особенно для структур типа $B 2$. Однако, по крайней мере, для ГЦК-структур, применение KMF к диффузии и упорядочению демонстрирует достаточно реалистичные результаты, качественно схожие с теми, которые 
получаются из кинетического метода Монте-Карло и в реальных экспериментах. Моделирование диффузии меченых атомов $\mathrm{Ni}$ и $\mathrm{Al}$ в системе $\mathrm{Ni}_{3} \mathrm{Al}$ демонстрирует более быструю диффузию атомов $\mathrm{Ni}$, чем $\mathrm{Al}$, что связано с более лёгкой диффузией атомов $\mathrm{Ni}$ по собственной подрешётке в сверхструктуре типа $L 1_{2}-\mathrm{Ni}_{3} \mathrm{Al}$. Также получены более высокая энергия активации для меченых атомов $\mathrm{Al}$ и её близкое значение к энергии активации кинетики упорядочения. Компьютерные эксперименты по кинетике упорядочения показали, что, в отличие от обменного механизма, при вакансионном механизме диффузии кинетика упорядочения по типу $L 1_{2}$ описывается двумя временами релаксации. Моделирование прерывистого процесса приповерхностной переориентации моноатомных плоскостей $\mathrm{Fe}$ и $\mathrm{Pt}$ в тонкой плёнке $\mathrm{FePt}$, в свою очередь, стало хорошим тестом для стохастического варианта KMF (SKMF). Тот факт, что введение стохастического шума оказалось необходимым для воспроизведения процесса поверхностной нуклеации, может свидетельствовать о корректности метода.

Keywords: kinetic mean-field method, tracer diffusion, ordering kinetics, atomistic simulation, intermetallics.

Ключові слова: кінетична середньопольова метода, дифузія значених атомів, кінетика впорядкування, атомістичне моделювання, інтерметаліди.

Ключевые слова: кинетический среднеполевой метод, диффузия меченых атомов, кинетика упорядочения, атомистическое моделирование, интерметаллиды.

(Received July 02, 2017)

\section{INTRODUCTION}

Simulation of ordering and atomic migration in ordered alloys was always the subject of Monte Carlo simulations [1-3]. Usually, such methods need a lot of computation time. In the present paper, the advantages and disadvantages of an alternative method are discussed. The method called 'kinetic mean field' was originally proposed by George Martin in 1990 [4] as a pseudo-1D-algorithm. The technique was then applied to nanofilms with diffusion asymmetry in the series of papers by Z. Erdelyi, D. Beke et al. [5-8], extended to $3 D$ [9], and recently generalized to first-order transformations by introducing dynamic noise of jump frequencies in the kinetic master equations ('stochastic KMF' (SKMF) [10].)

The Martin's version of KMF approach is not the only one [1114]. The mean-field approach is a very popular approximation when interactions between particles are approximated by interactions of particles with some effective field representing an averaged effect 
of the surrounding atoms.

In the widely used cluster variation method (CVM) (see, e.g., [15]), the averaging is based on parameterizing the atomic configuration by so-called cluster variables defined as probabilities for the finding clusters of atoms showing explicit configurations. The largest cluster taken into account determines the order of approximation.

In the present paper, we discuss the simplest mean-field approach-so called point (Bragg-Williams) approximation where only one-atom clusters are considered and the cluster variables are equal to average concentrations $C_{\mu}(i)$ of $\mu$-type atoms on particular lattice sites $i$. These concentrations have a meaning of probabilities $p_{\mu}(i)$ for the finding $\mu$-type atoms on $i$-lattice sites calculated over an ensemble of systems. In this approximation, all multisite correlations are neglected. In the case of a binary $A-B$ system, the pair probability $p_{A B}$ of the occupation of neighbouring $i$ and $j$ sites by $A$ and $B$ species is approximated by a product of unary probabilities: $p_{A B}(i, j)$ $=p_{A}(i) p_{B}(j)=C_{A}(i) C_{B}(j)$. Consequently, the energy of an $A$-atom residing on the $i$-site and interacting with $Z$ nearest neighbours reads as

$$
E_{A}=\sum_{i n=1}^{Z}\left(C_{A}(i n) V_{A A}+C_{B}(i n) V_{A B}\right),
$$

where $V_{\mu \nu}$ denotes the nearest-neighbour pair-interaction energies between $\mu$ - and $v$-atoms, in- $i$-site neighbour.

The approximation is analogous to the initial Weiss approximation of the 'molecular field' in magnetism. The mean-field method of static concentration waves suggested by Khachaturyan is widely applied to the description of phase transformations in alloys [11]. It was intensively developed to calculate, for example, the phase diagram of f.c.c. binary alloys [12], but also to model the kinetics of the phase transformations (for example, precipitation of $\mathrm{Ni}_{3} \mathrm{Al}$ from disordered solution) [13, 14]. The fundamental difference between Martin's approach and other kinetic mean-field approaches is the self-consistent introduction of jump frequencies using the actual interaction energies. In Khachaturyan's kinetics, the Onsager coefficients are, of course, proportional to the jump frequency, but this frequency is not related to the actual energy state of the system. In Martin's kinetics, the jump frequencies contain the energies of atomic configurations before the jump calculated within the meanfield approximation. That is the main reason why Martin's kinetic model directly leads to equilibrium distribution as a limiting case of zero fluxes.

The main kinetic equation of the original Martin's paper (written for the chain of parallel atomic planes-pseudo-1D-model) is just a master equation with self-consistently defined frequencies: 


$$
\begin{aligned}
\frac{d C_{i}}{d t}= & -Z_{v}\left[C_{i}\left(1-C_{i-1}\right) \Gamma_{i, i-1}-\left(1-C_{i}\right) C_{i-1} \Gamma_{i-1, i}+\right. \\
& \left.+C_{i}\left(1-C_{i+1}\right) \Gamma_{i, i+1}-\left(1-C_{i}\right) C_{i+1} \Gamma_{i+1, i}\right] .
\end{aligned}
$$

Here, $C_{i}$ is a probability of any site in the plane $i$ to be occupied by species $A, Z=Z_{l}+2 Z_{v}$ - total number of nearest neighbours, $Z_{l}$ denotes the number of nearest neighbours in the 'central' plane perpendicular to the concentration gradient, $Z_{v}$ is the number of nearest neighbours in the right-hand plane $i+1$ (or left-hand plane $i-1$ ),

$$
\Gamma_{i, i+1}=v \exp \left(-\frac{E_{i, i+1}}{k T}\right)
$$

is a frequency (probability per unit time) of exchange between an atom $A$ in the plane $i$ and an atom $B$ in the plane $i+1, E_{i, i+1}$ is a difference between the saddle point energy $E^{\text {saddle }}$ and the energy $\bar{E}_{i, i+1}$ of interactions of the two exchanging atoms with their neighbours before the exchange:

$$
E_{i, i+1}=E^{\text {saddle }}-\bar{E}_{i, i+1} .
$$

While the saddle-point energy $E^{\text {saddle }}$ is in most applications taken the same (e.g., equal to zero) for all exchanges (Fig. 1), the energies $\bar{E}_{i, i+1}$ are determined for each exchange in terms of the pairinteraction energies $V_{\mu v}$ usually evaluated by fitting to experimentally determined parameters of particular systems. In addition, it should be remarked that any change (increment/decrement) of $E^{\text {saddle }}$

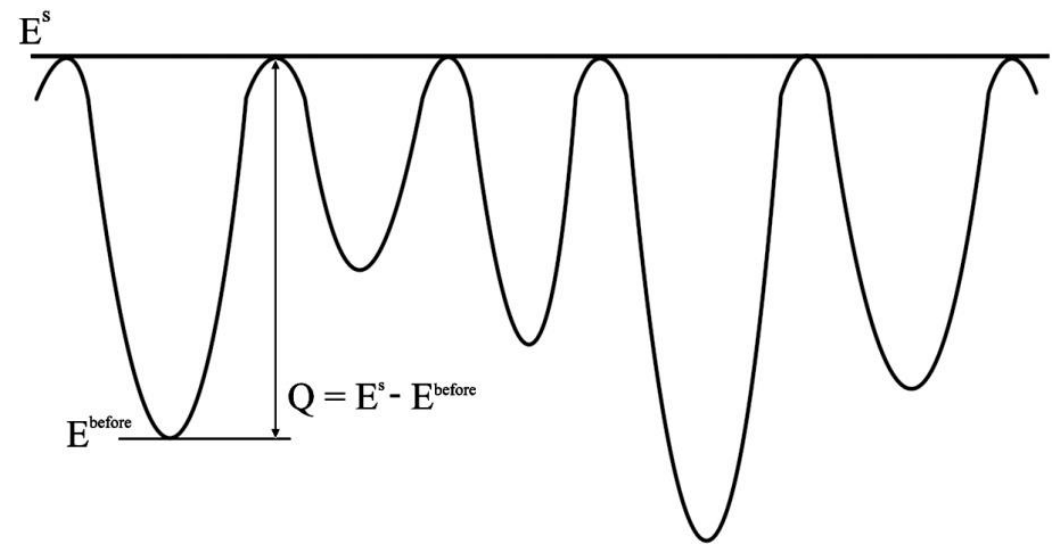

Fig. 1. Scheme of energy barriers under the assumption of universal saddle-point. (Analogous picture was suggested long ago by Kirill Gurov and can be found in the monograph of Former Soviet Union [16].) 
brings about a totally uniform change of currently appearing values of $E_{i, i+1}$. The same increment/decrement is thus transferred to the collective energy parameters-e.g., to the thermodynamic activation energy determined for any process modelled within this approach.

In the case of a binary system, the energy of the $A-B$ pair before their exchange is taken as

$$
\begin{gathered}
\bar{E}_{i, i+1}=Z_{v} C_{i+1} V_{A A}+Z_{v}\left(1-C_{i+1}\right) V_{A B}+Z_{v} C_{i-1} V_{A A}+Z_{v}\left(1-C_{i-1}\right) V_{A B}+ \\
+Z_{v} C_{i} V_{A A}+Z_{l}\left(1-C_{i}\right) V_{A B}+Z_{v} C_{i+2} V_{A B}+Z_{v}\left(1-C_{i+2}\right) V_{B B}+ \\
+Z_{v} C_{i} V_{A B}+Z_{v}\left(1-C_{i}\right) V_{B B}+Z_{l} C_{i+1} V_{A B}+Z_{l}\left(1-C_{i+1}\right) V_{B B} .
\end{gathered}
$$

The Debrecen team (Beke, Erdelyi et al.) applied this pseudo-1D method to initial stages of interdiffusion in the binary diffusion couples with a large difference between $V_{A A}$ and $V_{B B}$. Among other interesting results, they predicted a possibility of sharpening the concentration profile at the initial stage of interdiffusion (instead of a standard case of its broadening) [5,6]. This prediction was checked and proved experimentally. Another interesting prediction was a linear regime (instead of standard parabolic one) at similar conditions [7]. Finally, Debrecen team predicted that in strongly asymmetrical systems, ordering during diffusive formation of the $B 2$ structure may start far from stoichiometric concentrations [8].

In [9] almost trivial generalization of existing KMF scheme on $3 D$ case was suggested:

$$
\begin{gathered}
\frac{d C_{i}}{d t}=-C_{i} \sum_{j=1}^{Z}\left(1-C_{j}\right) \Gamma_{i, j}+\left(1-C_{i}\right) \sum_{j=1}^{Z} C_{j} \Gamma_{j, i}, \\
\Gamma_{i, j}=v \exp \left(\frac{-\left(E^{\text {saddle }}-\bar{E}_{i, j}\right)}{k T}\right), \\
\bar{E}_{i, j}=E_{i}^{A}+E_{j}^{B}, \\
E_{i}^{A}=V_{A A} \sum_{i n}^{Z} C_{i n}+V_{A B} \sum_{i n}^{Z}\left(1-C_{i n}\right), \\
E_{j}^{B}=V_{A B} \sum_{j n}^{Z} C_{j n}+V_{B B} \sum_{j n}^{Z}\left(1-C_{j n}\right) ;
\end{gathered}
$$

here, $\sum_{i n=1}^{Z}$ indicates the sum over the nearest neighbours of $i$-site, $\sum_{j n=1}^{Z}$ indicates the sum over nearest neighbours of $j$-site, which is in turn, one of the nearest neighbours of $i$-site (see Fig. 2).

Since the saddle point energy is a fitting parameter and the preexponential factor $v$ in Eq. (3) can be reasonably evaluated only for the vacancy mechanism, one cannot treat the time parameter $t$ in (6) as a real time. It is more convenient to rescale time and use the 


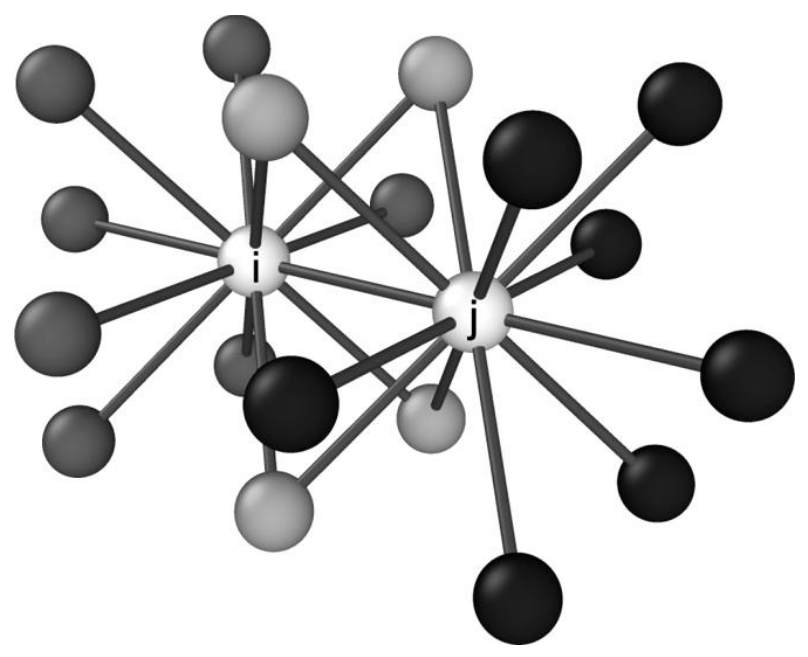

Fig. 2. The scheme of neighbours in the calculation of energy before exchange of atoms at the $i$ and $j$ sites within the KMF method. Grey and light-grey sites are the neighbours of $i$-site (index ' $i n$ ' in equations), black and light-grey sites are the neighbours of $j$-site (index ' $j n$ ' in equations). Light-grey sites are common neighbours for both $i$ and $j$.

dimensionless time. For this aim, it is convenient to rewrite the equations (7) and (8) as follows:

$$
\begin{gathered}
\bar{E}_{i(A) j(B)}=2 Z V_{A B}+(M-V) \sum_{i n=1}^{Z} C_{A}(i n)-(M+V) \sum_{j n=1}^{Z} C_{B}(j n)= \\
=Z\left(V_{A B}+V_{B B}\right)+(M-V) \sum_{i n=1}^{Z} C_{A}(i n)+(M+V) \sum_{j n=1}^{Z} C_{A}(j n), \\
\Gamma_{i, j}=\Gamma_{0} \tilde{\Gamma}_{i, j},
\end{gathered}
$$

where

$$
V=V_{A B}-\frac{V_{A A}+V_{B B}}{2}, \quad M=\frac{V_{A A}-V_{B B}}{2} .
$$

Here, the dimensionless frequency factor $\tilde{\Gamma}_{i, j}$ and the dimensionless pre-exponential factor $\Gamma_{0}$ are equal to

$$
\tilde{\Gamma}_{i, j}=\exp \left(\frac{(M-V) \sum_{i n=1}^{Z} C_{A}(i n)+(M+V) \sum_{j n=1}^{Z} C_{A}(j n)}{k T}\right),
$$




$$
\Gamma_{0}=v \exp \left(-\frac{E^{\text {saddle }}-\left(V_{A B}+V_{B B}\right) Z}{k T}\right),
$$

Dimensionless time can be defined as

$$
\tilde{t} \equiv \Gamma_{0} t .
$$

As one can see, the dimensionless time scaling is temperature dependent.

Recently, a scheme very similar to $3 D \mathrm{KMF}$ version [9] was introduced for the modelling of an ordering kinetics [17]. The formalism differs from the $3 D \mathrm{KMF}$ in three respects. They are as follow: (1) vacancy mechanism was introduced from the very beginning, (2) only homogeneous ordering was considered-concentration of any species $(A, B$, or vacancy $V)$ was the same for all given sublattice sites, (3) the saddle point energy was variable and followed the kinetic Monte Carlo (KMC) tradition: $E^{\text {saddle }}=E^{+}+\left(E^{\text {before }}+E^{\text {after }}\right) / 2$ with $E^{+}$depending exclusively on the kind of the jumping atom.

Being a deterministic formalism, the standard KMF method is not adequate to model discontinuous transformations triggered by fluctuations. To enable the modelling of first-order ordering transformations in f.c.c. lattice, the method was enriched by introducing the initial concentration noise (noise of initial probability on sites at atomic scale) [9].

In Ref. [10], the next logical step was introduced. Dynamic noise of frequencies (instead of or additionally to initial noise of concentrations) was introduced providing the possibility for the overcoming the nucleation barriers. This new version of the kinetic meanfield method was called as a stochastic kinetic mean-field (SKMF) method.

The master equation in SKMF can be written in the following form:

$$
\frac{d C_{i}}{d t}=-\sum_{j=1}^{Z}\left[C_{i}\left(1-C_{j}\right)\left(\Gamma_{i, j}+\delta \Gamma_{i, j}^{\mathrm{Lang}}\right)-\left(1-C_{i}\right) C_{j}\left(\Gamma_{j, i}+\delta \Gamma_{j, i}^{\mathrm{Lang}}\right)\right],
$$

where the Langevin noise of frequencies can be expressed as

$$
\delta \Gamma_{i, j}^{\mathrm{Lang}}=\frac{A_{n}}{\sqrt{d t}} \sqrt{3}(2 \cdot \text { rand }-1) .
$$

As shown in Ref. [10], changing the noise amplitude, one may tune the kinetic Monte Carlo with various numbers of runs. (We will not discuss here the special precautions made in SKMF to avoid the going of the probabilities beyond the interval [0,1]; see Ref. [10] in detail.) 


\section{KMF METHOD-APPLICATION TO TRACER DIFFUSION}

\subsection{KMF simulations implemented with the exchange mechanism of atomic migration}

Up to now, the only attempt for the KMF modelling of interdiffusion involved the method implemented with unphysical 'direct exchange' mechanism of atomic migration. However, as mentioned above, even with this unphysical assumption, the KMF was able to predict some real properties of diffusion in systems with large pairinteraction asymmetry $M$ (11). This method can be easily modified to model tracer diffusion. (Note that KMF with vacancy mechanism will be discussed in subsec. 2.2.) Of course, in KMF we cannot trace the trajectory of individual atoms (as, e.g., in Monte Carlo simulations). Therefore, we cannot use Einstein relation for the mean squared displacements of tracers. Instead, one can use the wellknown analytical solution for the point source. Assuming a binary $A-B$ system, we consider an $h$-thick layer located in the centre of a long sample, substitute the $A(B)$ atoms by $A^{*}\left(B^{*}\right)$ tracers and subsequently monitor the evolution of locally averaged tracer concentration profile. Local averaging, usually performed over two planes, is necessary since, for example, in the ordered lattice one may expect regular oscillations of tracers among two sublattices.

Denoting $C_{A(B)}$ as a total $A(B)$ atom concentration, $C_{A(B)}^{0}-A(B)$ atom concentration, $C_{A(B)}^{*}-A(B)$ tracer concentration, we have

$$
C_{A}=C_{A}^{*}+C_{A}^{0}, C_{B}=1-C_{A}^{0}-C_{A}^{*} .
$$

One expects the following time dependence of the locally averaged $C^{*}{ }_{A}(t, X)$ profile:

$$
\begin{gathered}
C_{A(B)}^{*}(t, X)=\frac{C_{A(B) 0}^{*} h}{\sqrt{4 \pi D_{A(B)}^{*} t}} \exp \left(-\frac{X^{2}}{4 D_{A(B)}^{*} t}\right), \\
\ln C_{A(B)}^{*}(t, X)=\mathrm{const}-\frac{1}{4 D_{A(B)}^{*} t} X^{2},
\end{gathered}
$$

where $X$ denotes the distance from the centre of the layer originally occupied by the tracer atoms. The slope of $\ln \left(C_{A(B)}^{*}(t, X) v s . X^{2}\right.$ yields the diffusivity scaled with respect to the simulation time units.

The kinetic equations are modified in almost trivial way:

$$
\frac{d C_{A}^{*}(i)}{d t}=-C_{A}^{*}(i) \sum_{k=1}^{Z} C_{A}^{0}(k) \Gamma_{i k}^{A^{*} A^{0}}-C_{A}^{*}(i) \sum_{k=1}^{Z} C_{B}(k) \Gamma_{i k}^{A^{*} B}+
$$




$$
\begin{gathered}
+C_{A}^{0}(i) \sum_{k=1}^{Z} C_{A}^{*}(k) \Gamma_{k i}^{A^{0} A^{*}}+C_{B}(i) \sum_{k=1}^{Z} C_{A}^{*}(k) \Gamma_{k i}^{B A^{*}}, \\
\frac{d C_{A}^{0}(i)}{d t}=-C_{A}^{0}(i) \sum_{k=1}^{Z} C_{A}^{*}(k) \Gamma_{i k}^{A^{0} A^{*}}-C_{A}^{0}(i) \sum_{k=1}^{Z} C_{B}(k) \Gamma_{i k}^{A^{0} B}+ \\
+C_{A}^{*}(i) \sum_{k=1}^{Z} C_{A}^{0}(k) \Gamma_{k i}^{A^{*} A^{0}}+C_{B}(i) \sum_{k=1}^{Z} C_{A}^{0}(k) \Gamma_{k i}^{B A^{0}}, \\
\Gamma_{i k}^{A^{*} A^{0}}=v \exp \left(-\frac{E^{\text {saddle }}-E_{A^{*} A^{0}}^{\text {before }}}{k T}\right), \\
E_{A^{*} A^{0}}^{\text {before }}=V_{A A} \sum_{i^{\prime}=1}^{Z}\left(C_{A}^{0}\left(i^{\prime}\right)+C_{A}^{*}\left(i^{\prime}\right)\right)+V_{A B} \sum_{i^{\prime}=1}^{Z} C_{B}\left(i^{\prime}\right)+ \\
+V_{A A} \sum_{k^{\prime}=1}^{Z}\left(C_{A}^{0}\left(k^{\prime}\right)+C_{A}^{*}\left(k^{\prime}\right)\right)+V_{A B} \sum_{k^{\prime}=1}^{Z} C_{B}\left(k^{\prime}\right), \\
\Gamma_{i k}^{A^{*} B}=v \exp \left(-\frac{E^{\mathrm{saddle}}-E_{A^{*} B}^{\mathrm{bere}}}{k T}\right), \\
E_{A^{*} B}^{\text {before }}=V_{A A} \sum_{i^{\prime}=1}^{Z}\left(C_{A}^{0}\left(i^{\prime}\right)+C_{A}^{*}\left(i^{\prime}\right)\right)+V_{A B} \sum_{i^{\prime}=1}^{Z} C_{B}\left(i^{\prime}\right)+ \\
+V_{A B} \sum_{k^{\prime}=1}^{Z}\left(C_{A}^{0}\left(k^{\prime}\right)+C_{A}^{*}\left(k^{\prime}\right)\right)+V_{B B} \sum_{k^{\prime}=1}^{Z} C_{B}\left(k^{\prime}\right), \\
E_{A^{0} B}^{\text {before }}=V_{A A} \sum_{i^{\prime}=1}^{Z}\left(C_{A}^{0}\left(i^{\prime}\right)+C_{A}^{*}\left(i^{\prime}\right)\right)+V_{A B} \sum_{i^{\prime}=1}^{Z} C_{B}\left(i^{\prime}\right)+ \\
\sum_{k^{\prime}=1}^{Z}\left(C_{A}^{0}\left(k^{\prime}\right)+C_{A}^{*}\left(k^{\prime}\right)\right)+V_{B B} \sum_{k^{\prime}=1}^{Z} C_{B}\left(k^{\prime}\right) .
\end{gathered}
$$

Redistribution of the probabilities (concentrations) is calculated after each time step according to Eqs. (19)-(25). As a result, the profile of tracers is found. Its typical shape for the tracer diffusion in the ordered alloy is presented in Fig. 3.

As previously mentioned, the linear regression of $\ln C_{A(B)}^{*}(t, X)$ vs. $X^{2} /(4 t)$ yields then the diffusivity scaled with respect to the simulation time units (Fig. 4).

Standard Arrhenius analysis of the temperature dependence of the evaluated diffusivity yields the thermodynamic activation energy $Q_{A(B)}$ for the $A(B)$ tracer diffusion. The possible curvature of the Arrhenius plot indicates that this activation energy is temperature dependent, e.g., due to 'chemical' (atomic) ordering. 

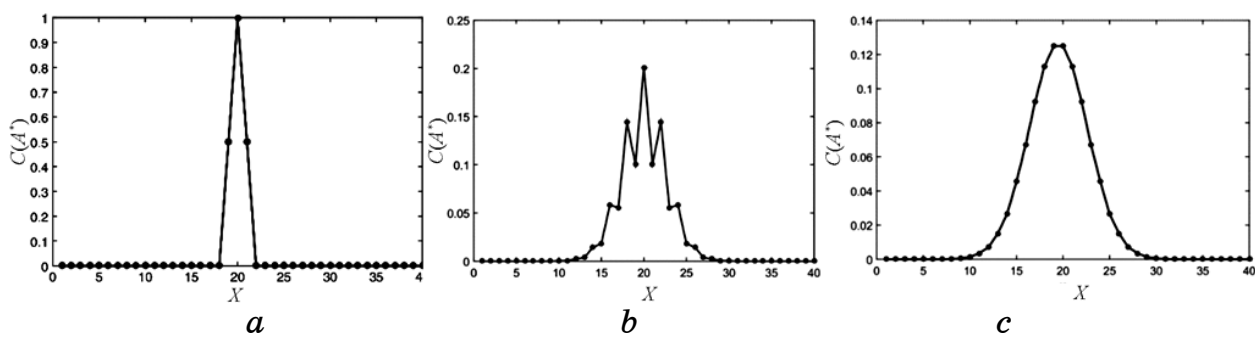

Fig. 3. The typical tracer concentration profile resulting from diffusion within the ordered alloy from three planes initially occupied by the tracer atoms: $(a)$ initial profile, $(b)$ profile after $t>0$ without averaging, $(c)$ profile after $t>0$ averaged over each two neighbouring planes.

The use of the dimensionless time (see Eqs. (12) and (13)) causes, however, that the right value of $Q_{A(B)}$ is shifted with respect to the slope $a^{\text {Arrhenius }}$ of the Arrhenius plot by $E^{\text {saddle }}-\left(V_{A B}+V_{B B}\right) Z$ :

$$
Q_{A(B)}=a^{\text {Arrhenius }}+E^{\text {saddle }}-\left(V_{A B}+V_{B B}\right) Z \text {. }
$$

Consideration of any relationship between the values of $Q_{A(B)}$ and the experimental thermodynamic activation energy for the tracer diffusion is reasonable provided the relationship between the KMF time and real time is found.

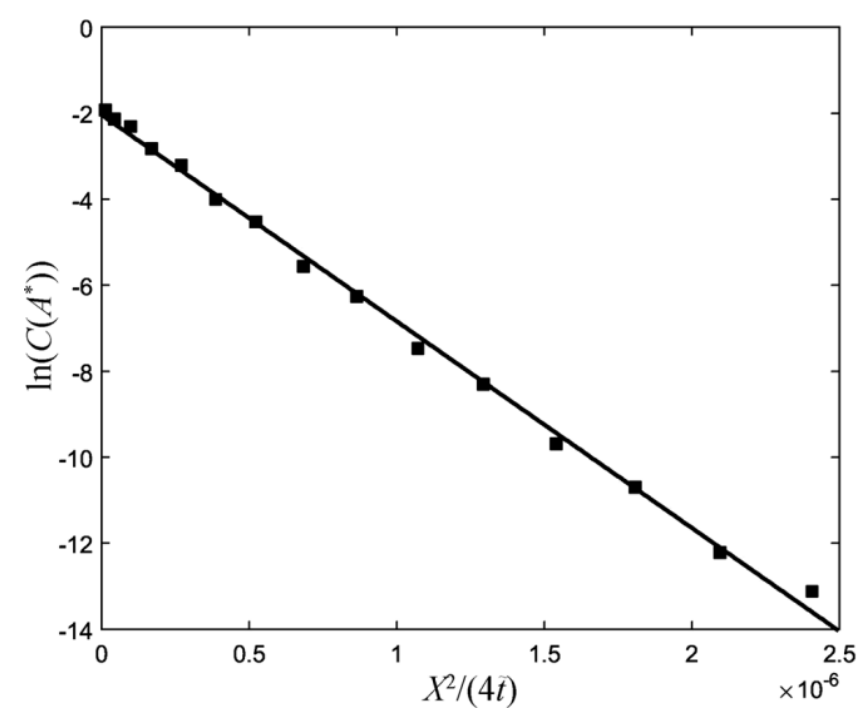

Fig. 4. Typical dependence of the logarithm of locally averaged local tracer concentration on squared distance scaled with the dimensionless time (Eq. (13)). 


\subsection{KMF simulations implemented with vacancy mechanism of atomic migration}

The major limitation of any kinetic mean field approach to vacancy mechanism is a lack of proper account of time correlations in vacancy mechanism diffusion. In real situation, system always has some 'memory' about last few jumps of any atom: if atom has just exchange places with neighbour vacancy, its next jump is not totally random; there is a significant probability of reverse exchange. Any mean field theory, by definition, has no 'memory'. Therefore, it is impossible, for example, to find correlation factor for the tracer diffusion by vacancy mechanism. It should be calculated, for example, by kinetic Monte Carlo method. Therefore, in calculation of tracer diffusivities by SKMF method, we are not pretending on accurate values of diffusion coefficients and instead we concentrate on determining of activation energy of diffusion. Thus, in the following when we speak about the frequency of exchanges $A \leftrightarrow V$ or $B \leftrightarrow V$, we keep in mind, actually, the series of correlated vacancyatom exchanges leading to resulting atomic displacement into neighbouring site. Kinetic Monte Carlo with vacancy mechanism is more 'honest' in this sense (but much less computational timesaving). Nevertheless, as we will see below, comparison of KMF and KMC gives qualitatively very similar results. The following kinetic equations describe the evolution of a system where only nearestneighbour atom-vacancy exchanges are realized:

$$
\begin{gathered}
\frac{d C_{v}(i)}{d t}=-C_{v}(i) \sum_{k=1}^{Z}\left(C_{A}^{*}(k)+C_{A}^{0}(k)\right) \Gamma_{k i}^{A V}-C_{v}(i) \sum_{k=1}^{Z} C_{B}(k) \Gamma_{k i}^{B V}+ \\
+\left(C_{A}^{*}(i)+C_{A}^{0}(i)\right) \sum_{k=1}^{Z} C_{v}(k) \Gamma_{i k}^{A V}+C_{B}(i) \sum_{k=1}^{Z} C_{v}(k) \Gamma_{i k}^{B V} \\
\frac{d C_{B}(i)}{d t}=-C_{B}(i) \sum_{k=1}^{Z} C_{v}(k) \Gamma_{i k}^{B V}+C_{v}(i) \sum_{k=1}^{Z} C_{B}(k) \Gamma_{k i}^{B V} \\
\frac{d C_{A}^{*}(i)}{d t}=-C_{A}^{*}(i) \sum_{k=1}^{Z} C_{v}(k) \Gamma_{i k}^{A V}+C_{v}(i) \sum_{k=1}^{Z} C_{A}^{*}(k) \Gamma_{k i}^{A V} \\
\frac{d C_{A}^{0}(i)}{d t}=-C_{A}^{0}(i) \sum_{k=1}^{Z} C_{v}(k) \Gamma_{i k}^{A V}+C_{v}(i) \sum_{k=1}^{Z} C_{A}^{0}(k) \Gamma_{k i}^{A V}
\end{gathered}
$$

Since vacancies are much more mobile than atoms (at vacancy concentration $1 \cdot 10^{-6}$, the vacancies are million times more mobile than atoms), the evolution of the vacancy subsystem is much faster than that of the main components. It means that, for the direct numerical solution of KMF equations (27)-(30), one needs the time 
step $d t$ circa million times smaller than in the case of the exchange mechanism. This makes the tailoring of the tracer concentration profile (or other profiles) practically unreachable, due to limitations of the computation time. In the vacancy mediated diffusion, one encounters, therefore, the hierarchy in the chain of processes and characteristic times, which was analyzed in detail by Bogolyubov in Ref. [18]. As faster processes usually accommodate to slower ones, their analysis may be performed within the steady-state approximation. Therefore, following the ideas of Gurov and co-authors in Ref. [19], we suggested to use the steady-state approximation for the vacancies, to accommodate the vacancy profile to the slowly changing profile of the main components [20], [21]. The steady-state approximation for the vacancies transforms Eq. (27) from the differential form to the iteration scheme for the finding of a steady-state vacancy distribution:

$$
C_{v}^{\mathrm{iter}+1}(i)=\frac{\left(C_{A}^{*}(i)+C_{A}^{0}(i)\right) \sum_{k=1}^{Z} C_{v}^{\mathrm{iter}}(k) \Gamma_{i k}^{A V}+C_{B}(i) \sum_{k=1}^{Z} C_{v}^{\mathrm{iter}}(k) \Gamma_{i k}^{B V}}{\sum_{k=1}^{Z}\left(C_{A}^{*}(k)+C_{A}^{0}(k)\right) \Gamma_{k i}^{A V}+C_{B}(k) \Gamma_{k i}^{B V}} .
$$

To satisfy the constraint of the frozen vacancy sinks or sources, we use renormalization of the vacancy profile at each iteration step:

$$
C_{v}^{\mathrm{iter}+1}(i)=\frac{S_{0}}{S} C_{v}^{\mathrm{iter}+1}(i), \quad S=\sum C_{v}^{\mathrm{iter}+1}, \quad S_{0}=\sum C_{v}^{0} .
$$

The standard criterion for the iteration convergence is applied:

$$
\left|\bar{C}_{v}^{i \operatorname{ter}+1}-\bar{C}_{v}^{\mathrm{iter}}\right|<\varepsilon .
$$

It is assumed that

$$
\begin{aligned}
& \Gamma_{k i}^{A V}=v_{0 A} \exp \left(-\frac{E^{\text {saddle }}-E_{A V}^{\text {before }}}{k T}\right), \\
& \Gamma_{k i}^{B V}=v_{0 B} \exp \left(-\frac{E^{\text {saddle }}-E_{B V}^{\text {before }}}{k T}\right),
\end{aligned}
$$

where

$$
\begin{aligned}
E_{A V(k \rightarrow i)}^{\text {before }}= & \sum_{k^{\prime}=1}^{Z}\left(C_{A}^{0}\left(k^{\prime}\right)+C_{A}^{*}\left(k^{\prime}\right)\right) V_{A A}+C_{B}\left(k^{\prime}\right) V_{A B}+C_{v}\left(k^{\prime}\right) V_{A V}+ \\
& +\sum_{i^{\prime}=1}^{Z}\left(C_{A}^{0}\left(i^{\prime}\right)+C_{A}^{*}\left(i^{\prime}\right)\right) V_{V A}+C_{B}\left(i^{\prime}\right) V_{V B}+C_{V}\left(i^{\prime}\right) V_{V V},
\end{aligned}
$$




$$
\begin{aligned}
E_{B V(k \rightarrow i)}^{\text {before }}= & \sum_{k^{\prime}=1}^{Z}\left(C_{A}^{0}\left(k^{\prime}\right)+C_{A}^{*}\left(k^{\prime}\right)\right) V_{B A}+C_{B}\left(k^{\prime}\right) V_{B B}+C_{v}\left(k^{\prime}\right) V_{B V}+ \\
& +\sum_{i^{\prime}=1}^{Z}\left(C_{A}^{0}\left(i^{\prime}\right)+C_{A}^{*}\left(i^{\prime}\right)\right) V_{V A}+C_{B}\left(i^{\prime}\right) V_{V B}+C_{V}\left(i^{\prime}\right) V_{V V}, \\
E_{A V(i \rightarrow k)}^{\text {before }}= & \sum_{i^{\prime}=1}^{Z}\left(C_{A}^{0}\left(i^{\prime}\right)+C_{A}^{*}\left(i^{\prime}\right)\right) V_{A A}+C_{B}\left(i^{\prime}\right) V_{A B}+C_{v}\left(i^{\prime}\right) V_{A V}+ \\
& +\sum_{k^{\prime}=1}^{Z}\left(C_{A}^{0}\left(k^{\prime}\right)+C_{A}^{*}\left(k^{\prime}\right)\right) V_{V A}+C_{B}\left(k^{\prime}\right) V_{V B}+C_{V}\left(k^{\prime}\right) V_{V V}, \\
E_{B V(i \rightarrow k)}^{\text {before }}= & \sum_{i^{\prime}=1}^{Z}\left(C_{A}^{0}\left(i^{\prime}\right)+C_{A}^{*}\left(i^{\prime}\right)\right) V_{B A}+C_{B}\left(i^{\prime}\right) V_{B B}+C_{v}\left(i^{\prime}\right) V_{B V}+ \\
& +\sum_{k^{\prime}=1}^{Z}\left(C_{A}^{0}\left(k^{\prime}\right)+C_{A}^{*}\left(k^{\prime}\right)\right) V_{V A}+C_{B}\left(k^{\prime}\right) V_{V B}+C_{V}\left(k^{\prime}\right) V_{V V} \cdot
\end{aligned}
$$

Assuming zero interactions with and between the vacancies, one obtains:

$$
E_{A V(k \rightarrow i)}^{\text {before }}=\sum_{k^{\prime}=1}^{Z}\left(C_{A}^{0}\left(k^{\prime}\right)+C_{A}^{*}\left(k^{\prime}\right)\right) V_{A A}+C_{B}\left(k^{\prime}\right) V_{A B},
$$

or

$$
\begin{gathered}
E_{A V(k \rightarrow i)}^{\text {before }}=Z V_{A B}+\left(V_{A A}-V_{A B}\right) \sum_{k^{\prime}=1}^{Z}\left(C_{A}^{0}\left(k^{\prime}\right)+C_{A}^{*}\left(k^{\prime}\right)\right), \\
E_{B V(k \rightarrow i)}^{\text {before }}=Z V_{A B}+\left(V_{B B}-V_{A B}\right) \sum_{k^{\prime}=1}^{Z} C_{B}\left(k^{\prime}\right) .
\end{gathered}
$$

Similarly, as in the case of the exchange mechanism, one can introduce the following dimensionless parameters:

$$
\begin{aligned}
& \Gamma_{k, i}(A \leftrightarrow V)=\Gamma_{0} \tilde{\Gamma}_{k, i}(A \leftrightarrow V), \\
& \Gamma_{k, i}(B \leftrightarrow V)=\Gamma_{0} \tilde{\Gamma}_{k, i}(B \leftrightarrow V),
\end{aligned}
$$

where the dimensionless frequencies and the pre-exponential factor are equal to

$$
\begin{aligned}
& \tilde{\Gamma}_{k, i}(A \leftrightarrow V)=\sqrt{\frac{v_{0 A}}{v_{0 B}}} \exp \left(-(V-M) \sum_{i n=1}^{Z} C_{A}(k n) / k T\right), \\
& \tilde{\Gamma}_{k, i}(B \leftrightarrow V)=\sqrt{\frac{v_{0 B}}{v_{0 A}}} \exp \left(-(V+M) \sum_{i n=1}^{Z} C_{B}(k n) /(k T)\right),
\end{aligned}
$$




$$
\Gamma_{0}=\sqrt{v_{0 A} v_{0 B}} \exp \left(-\frac{E^{\text {saddle }}-V_{A B} Z}{k T}\right) .
$$

The dimensionless time is then defined as

$$
\tilde{t} \equiv \Gamma_{0} t .
$$

As the temperature-dependent dimensionless time scaling may again lead to the inversion of the slopes of the Arrhenius plots of the evaluated diffusivities (Eq. (26)), usual dimensional parameters for the time and frequency defined by Eqs. (34) were applied in the simulations for the vacancy mechanism-in contrary to the case of the exchange mechanism, in which the meaning of the preexponential factor is ambiguous.

\section{KMF METHOD-APPLICATION TO CHEMICAL ORDERING}

\subsection{General relationships}

The validity of the KMF method in the field of thermodynamics and kinetics of ordering in f.c.c. alloys has been recently checked [20]. For the reasons described in Sec. 1 (atomic configurations parameterized within point approximation), only long-range order (LRO) phenomena can be modelled by means of the KMF version used in the present work.

The degree of LRO is most often quantified by means of the Bragg-Williams parameters. In the case of binary $A-B$ systems whose crystalline structure is composed of two sublattices (I and II), the parameter is defined as

$$
\eta=\frac{p_{A}^{\mathrm{I}}-C_{A}}{1-v^{\mathrm{I}}}=\frac{p_{B}^{\mathrm{II}}-C_{B}}{1-v^{\mathrm{II}}},
$$

where

$$
p_{A(B)}^{\mathrm{I}(\mathrm{II})}=\frac{N_{A(B)}^{\mathrm{I}(\mathrm{II})}}{N^{\mathrm{I}(\mathrm{II})}}, \quad v^{\mathrm{I}(\mathrm{II})}=\frac{N^{\mathrm{I}(\mathrm{II})}}{N^{\mathrm{I}}+N^{\mathrm{II}}}
$$

denote the probability to find $A$-type ( $B$-type) atom at the sublattice I (II) and the fraction of I (II) sublattice sites, respectively.

For the sake of KMF, a local analogue of the LRO parameter (45) must be defined, e.g., by considering a cluster with the same atomic fractions of the components and vacancies as the whole crystal. The cluster should contain sites belonging to all sublattices in proportions equal to the global ones. Generally, it may contain both 'en- 
tire' sites and their 'fractions' (if the case of sites shared with neighbouring clusters). The sublattice fractions $v^{\mathrm{I}(\mathrm{II})}$ are then calculated according to Eq. (46) with

$$
N^{\mathrm{I}}=\sum_{i 1=1}^{M^{\mathrm{I}}} 1 / \operatorname{share}(i 1), \quad N^{\mathrm{II}}=\sum_{i 2=1}^{M^{\mathrm{II}}} 1 / \operatorname{share}(i 2),
$$

where the summations are performed over all $M^{\mathrm{I}}\left(M^{\mathrm{II}}\right)$ sublattice sites belonging entirely or partially to the cluster; share $(i)$ is a number of neighbouring clusters which share $i$-th site, so that $1 / \operatorname{share}(i)$ is a fraction of site $i$ in the cluster. One should calculate the local atomic concentrations in the cluster as

$$
\begin{aligned}
& C_{A}= \frac{\sum_{i 1=1}^{M^{\mathrm{I}}} C_{A}(i 1) / \operatorname{share}(i 1)+\sum_{i 2=1}^{M^{\mathrm{II}}} C_{A}(i 2) / \operatorname{share}(i 2)}{N^{\mathrm{I}}+N^{\mathrm{II}}}, \\
& C_{B}=\frac{\sum_{i 1=1}^{M^{\mathrm{I}}} C_{B}(i 1) / \operatorname{share}(i 1)+\sum_{i 2=1}^{M^{\mathrm{II}}} C_{B}(i 2) / \operatorname{share}(i 2)}{N^{\mathrm{I}}+N^{\mathrm{II}}} .
\end{aligned}
$$

The $a$ priori probabilities for the sublattices being occupied by the $A$ and $B$ atoms are calculated according to the following formulas:

$$
p_{A}^{\mathrm{I}}=\frac{\sum_{i 1=1}^{M^{\mathrm{I}}} C_{A}(i 1) / \operatorname{share}(i 1)}{N^{\mathrm{I}}}, \quad p_{B}^{\mathrm{II}}=\frac{\sum_{i 2=1}^{M^{\mathrm{II}}} C_{A}(i 2) / \operatorname{share}(i 2)}{N^{\mathrm{II}}} .
$$

We choose a cluster composed of the central site and 12 nearest neighbours. Such choice of the smallest possible cluster might be preferable for the describing of the systems with very sharp concentration gradients. Two neighbouring clusters are shown in Fig. 5.

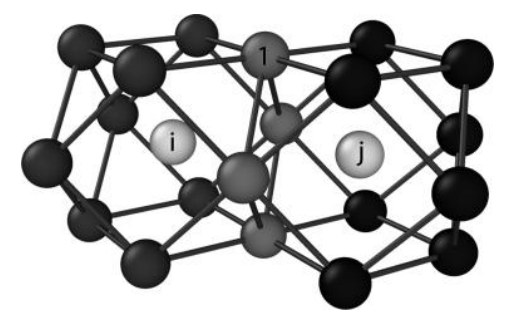

Fig. 5. Two clusters used for the calculation of the local LRO at $i$ and $j$ sites. For example, site 1 belongs to both of them as well as to two more clusters above. In total, the site 1 belongs simultaneously to 4 clusters, so that only $j$ of it belongs to the given cluster. The same can be shown for all sites around $i$. 
They share four common sites. One cluster consists of one central site ( share $=1$ ) and 12 boundary sites (share $=4$ ). Indeed, one can easily check that each boundary site is common for the four clusters. Hence, the total number of 'pure' sites is $N^{\mathrm{I}}+N^{\mathrm{II}}=1+12 / 4=4$. The central site may belong to one of 4 simple cubic lattices, which form an f.c.c. lattice. For each case, one should calculate its own 'local' LRO parameter. Three simple cubic lattices form a majority sublattice of $L 1_{2}$ structure (face centres), the 4 -th simple cubic lattice is a minority sublattice of this structure (cube corners).

If we assume that the central site of the cluster belongs to the majority sublattice I, then 8 of 12 neighbours also belong to the same sublattice but only $j$ of them belong to the given cluster. The remaining 4 neighbours belong to sublattice II but only $j$ of them belong to the given cluster. Hence,

$$
\begin{aligned}
& M^{\mathrm{I}}=1+8=9, \quad N^{\mathrm{I}}=1+8 / 4=3, \\
& M^{\mathrm{II}}=0+4=4, \quad N^{\mathrm{I}}=0+4 / 4=1 .
\end{aligned}
$$

If we assume that the central site of the cluster belongs to the minority sublattice II, then all 12 neighbours belong to the counterpart majority sublattice but again, only $j$ of them belong to the given cluster. Hence,

$$
\begin{aligned}
& M^{\mathrm{I}}=0+12=12, \quad N^{\mathrm{I}}=0+12 / 4=3, \\
& M^{\mathrm{II}}=1+0=1, \quad N^{\mathrm{I}}=1+0 / 4=1 .
\end{aligned}
$$

As mentioned above, each site may belong a priori to 4 simple cubic sublattices of f.c.c. lattice: three of them correspond to the majority sublattice of the $A_{3} B$ structure and the remaining one-to the minority sublattice. Of course, in general, all four versions should be checked and compared. Namely, if an $i$-site is considered as belonging to the majority sublattice of the $L 1_{2}$ superstructure and is occupied by a majority component, then there exist 3 ways to choose two planes of the same majority sublattice out of three mutually perpendicular planes containing the given site. Each choice corresponds to some value of local order parameter. Then three LRO parameters can be calculated depending on the choice of 8 neighbouring sites (out of 12) belonging to the same sublattice:

$$
\eta_{1,2,3}^{\mathrm{I}}(i)=\frac{\frac{C_{A}(i)+\frac{1}{4} \sum_{n n=1}^{8} C_{A}(n n)}{3}-\frac{C_{A}(i)+\frac{1}{4} \sum_{n n=1}^{12} C_{A}(n n)}{4}}{1-3 / 4} .
$$

If the $i$-site is treated as belonging to the minority sublattice, 
then the local LRO parameter can be defined as:

$$
\eta_{4}^{\mathrm{II}}(i)=\frac{C_{A}(i)-\frac{C_{A}(i)+\frac{1}{4} \sum_{n n=1}^{12} C_{A}(n n)}{4}}{1-1 / 4} .
$$

One can easily check that the above 'local LRO' parameters defined for each site are equal to 1 in the case of perfect order provided the sublattices are appropriately chosen. In the case of incorrect choice of the sublattice, the value of $\eta$ is $1 / 3$.

The correct order parameter corresponding to the given $i$-site is thus the one that shows maximum modulus.

\subsection{KMF simulation of ordering implemented with the exchange mechanism of atomic migration}

To avoid the formation and consequent competition of the antiphase domains, the study of the ordering kinetics described here always start from the homogeneous and perfectly ordered structure (i.e. from $T=0 \mathrm{~K})$. Temperature is then instantly increased to some higher value, and partial disordering of the ideal single domain starts, leading to a new degree of LRO. Once the system equilibration is observed, the procedure is repeated by again abruptly raising the temperature.

\subsection{KMF of ordering implemented with the vacancy mechanism of atomic migration}

In the case of the vacancy mechanism, the scheme is almost the same. Simulation additionally allows determining the equilibrium vacancy distribution (i.e. LRO) on the sublattices. The simulations start with a uniformly distributed arbitrary vacancy concentration (probability per site). During ordering, vacancies are redistributed among sublattices. Therefore, despite an arbitrary value of the vacancy concentration, the equilibrium ratio of vacancy concentrations at sublattices may be determined. (So far, the sinks and sources of vacancies, providing equilibrium of vacancy concentrations, are not included in the SKMF model.)

\section{KMF-SIMULATION RESULTS FOR THE BINARY SYSTEM WITH $L 1_{2}$-TYPE STRUCTURE}

The procedures described in sections 1 and 3 were applied to simu- 
late the $A_{3} B$ system mimicking the intermetallic compound $\mathrm{Ni}_{3} \mathrm{Al}$. The nearest-neighbour pair interaction parameters $\left(V_{A A}=-0.3 \mathrm{eV}\right.$, $V_{B B}=-0.15 \mathrm{eV}$, and $V_{A B}=-0.295 \mathrm{eV}$ ) used in the simulation were fitted in Ref. [23] to reproduce the properties of the phase $\gamma-\mathrm{Ni}_{3} \mathrm{Al}$.

\subsection{Simulations implemented with the exchange mechanism of atomic migration}

Arrhenius plots of the self(tracer)-diffusion coefficient of both $A$ (majority) and $B$ (minority) components are shown in Fig. 6. As explained in Sec. 2.1, their slopes $a^{\text {Arrhenius }}$ are related to the thermodynamic activation energies $Q_{A}$ and $Q_{B}$ for the $A$ - and $B$-tracer diffusion according to Eq. (26).

According to Eq. (24), one obtains:

$$
\begin{aligned}
Q_{A} & =1.1793 \cdot 10^{-19} \mathrm{~J}+E^{\text {saddle }}-\left(V_{A B}+V_{B B}\right) Z \approx \\
& \approx 1.18 \cdot 10^{-19} \mathrm{~J}+E^{\text {saddle }}-\left(V_{A B}+V_{B B}\right) Z, \\
Q_{B} & =2.4335 \cdot 10^{-19} \mathrm{~J}+E^{\text {saddle }}-\left(V_{A B}+V_{B B}\right) Z \approx \\
& \approx 2.43 \cdot 10^{-19} \mathrm{~J}+E^{\text {saddle }}-\left(V_{A B}+V_{B B}\right) Z .
\end{aligned}
$$

Comparing the mentioned above with the experimental result $Q_{\mathrm{Ni}} \approx$

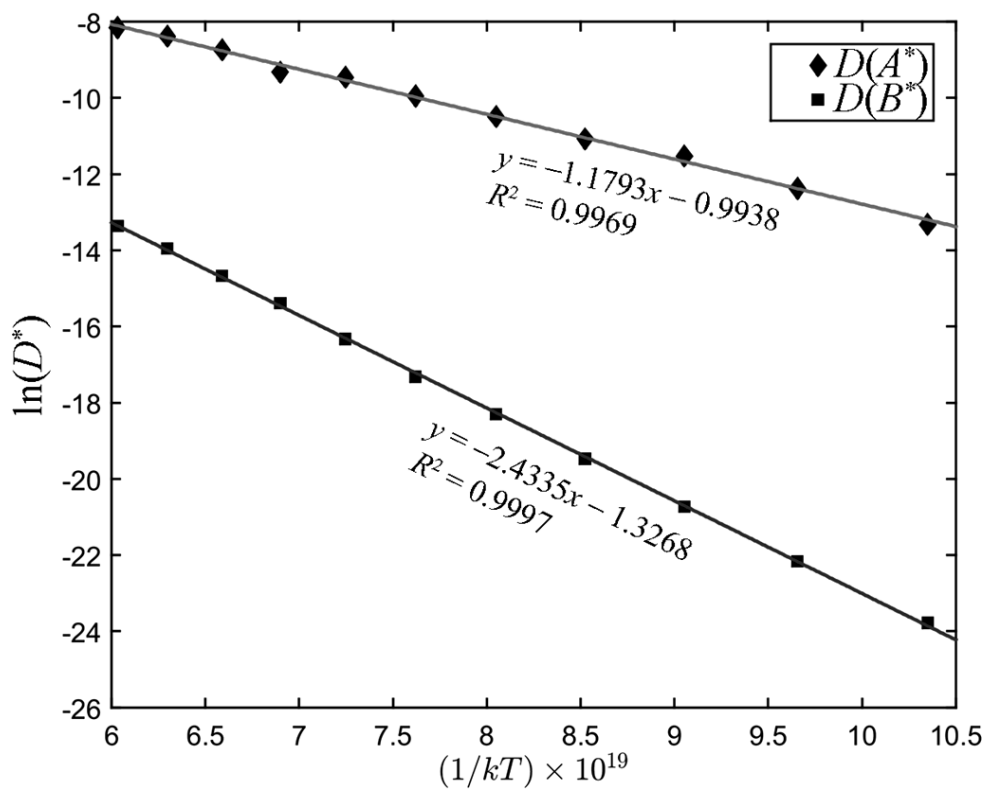

Fig. 6. Arrhenius plots of the $A$ - and $B$-tracer diffusivities in $A_{3} B\left(\mathrm{Ni}_{3} \mathrm{Al}\right)$ evaluated with the exchange mechanism of atomic migration. 
$\approx 3 \mathrm{eV}=4.8 \cdot 10^{-19} \mathrm{~J}[24]$, one can estimate

$$
E^{\text {saddle }}-\left(V_{A B}+V_{B B}\right) Z \approx 3.62 \cdot 10^{-19} \mathrm{~J},
$$

and consequently

$$
Q_{\mathrm{Al}} \approx 6.05 \cdot 10^{-19} \mathrm{~J}, \quad Q_{B} / Q_{A} \approx 1.27 .
$$

Higher activation energy for the tracer diffusion of the minority component in the $L 1_{2}$-ordered binary system, $B(\mathrm{Al})$ in $A_{3} B\left(\mathrm{Ni}_{3} \mathrm{Al}\right)$, is in agreement with the experimental results which, due to a lack of appropriate $\mathrm{Al}$ tracer, mostly concern the diffusion of admixture elements substituting for the $\mathrm{Al}$ atoms in $\mathrm{Ni}_{3} \mathrm{Al}$ (see, e.g., [3] and [25]). Higher diffusivity of $\mathrm{Ni}$ and lower value of $Q_{\mathrm{Ni}}$ results from the fact that in contrary to $\mathrm{Al}$, Ni can diffuse within its own sublattice.

The KMF simulation of 'order-order' kinetics yielded the following results: the 'order-order' relaxation isotherms fitted the single exponential

$$
\frac{\eta(t)-\eta(\infty)}{1-\eta(\infty)}=\exp \left(-\frac{t}{\tau}\right)
$$

The linear Arrhenius plot of the dimensionless relaxation time $\tau$

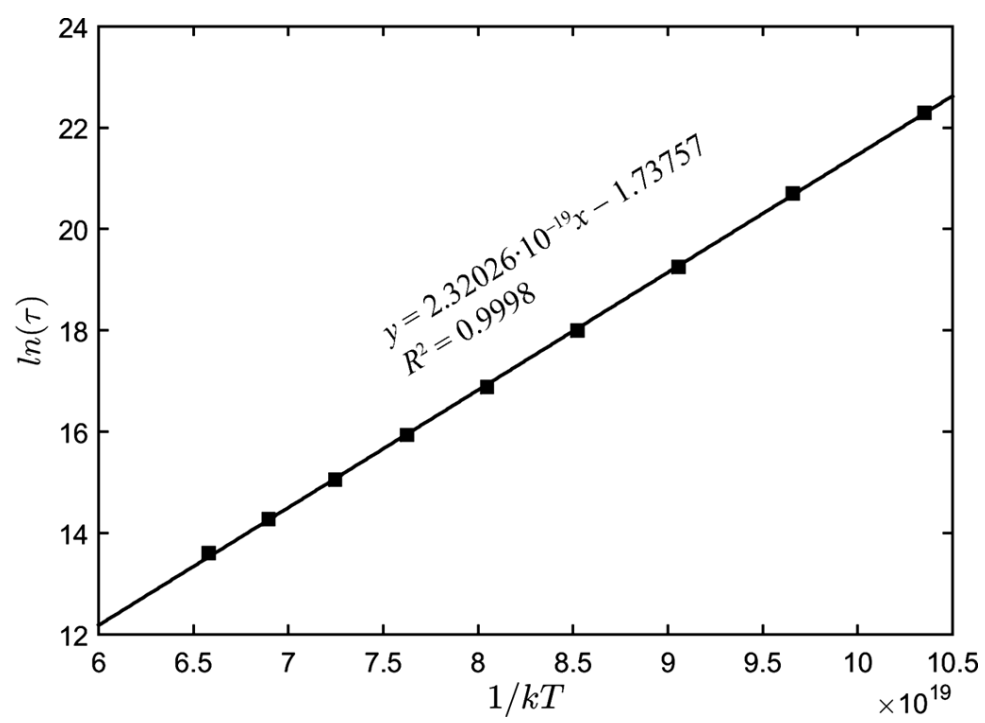

Fig. 7. Arrhenius plot of the relaxation time for the 'order-order' kinetics in $A_{3} B\left(\mathrm{Ni}_{3} \mathrm{Al}\right)$ evaluated with the exchange mechanism of atomic migration. 
(Fig. 7) indicates its standard temperature dependence:

$$
\tau=\tau_{0} \exp \left(\frac{Q^{\text {ordering }}}{k T}\right) .
$$

The slope $a^{\text {Arrhenius }}=2.32 \cdot 10^{-19} \mathrm{~J}$ of the Arrhenius plot is, however, again related to the thermodynamic activation energy $Q^{\text {ordering }}$ for the 'order-order' kinetics according to Eq. (26).

Using the estimation of Eq. (53), one obtains

$$
Q^{\text {ordering }}=2.32 \cdot 10^{-19} \mathrm{~J}+E^{\text {saddle }}-\left(V_{A B}+V_{B B}\right) Z \approx 5.9 \cdot 10^{-19} \mathrm{~J},
$$

which indicates that the activation energy for the 'order-order' kinetics in the simulated $L 1_{2}$-ordered $A_{3} B$ binary, is quite close to the activation energy for the minority tracer $\left(B^{*}\right)$ diffusion.

\subsection{Simulations implemented with the vacancy mechanism of atomic migration}

The simulations were carried out with arbitrarily chosen fixed vacancy concentration of $C_{v}=10^{-4}$. Figure 8 shows the Arrhenius plots

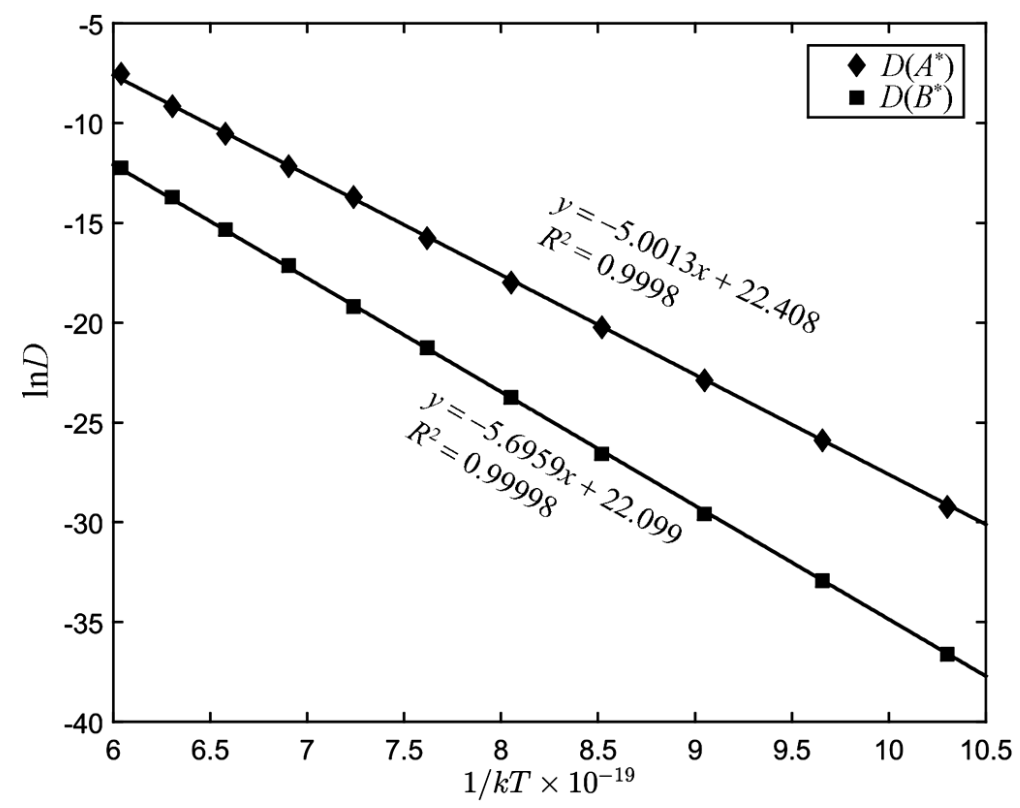

Fig. 8. Arrhenius plots of the $A$ - and $B$-tracer diffusivities in $A_{3} B\left(\mathrm{Ni}_{3} \mathrm{Al}\right)$ evaluated with the vacancy mechanism of atomic migration. 
of the $A$ - and $B$-tracer diffusivities.

As we remarked in Sec. 1, the constant value of the $E^{\text {saddle }}$ makes that its change linearly scales the thermodynamic activation energy. The thermodynamic activation energy $Q_{A}$ for the $A$-tracer diffusion may thus be adjusted to the experimental value of $Q_{\mathrm{Ni}}$ by adding an appropriate correction $\Delta E^{\text {saddle }}$ to the slope $a^{\text {Arrhenius }}$ of the Arrhenius plot of the $A$-tracer diffusivity in Fig. 8:

$$
Q_{A} \approx 5.00 \cdot 10^{-19} \mathrm{~J}+\Delta E^{\text {saddle }} .
$$

In view of the value of $Q_{\mathrm{Ni}}[24]$,

$$
\Delta E^{\text {saddle }} \approx-0.20 \cdot 10^{-19} \mathrm{~J},
$$

and we obtain

$$
Q_{B} \approx 5.70 \cdot 10^{-19} \mathrm{~J}+\Delta E^{\text {saddle }}=5.5 \times 10^{-19} \mathrm{eV}>Q_{A} .
$$

This is in a perfect qualitative agreement with the result obtained within the exchange mechanism of atomic migration.

A typical example of the 'order-order' relaxation isotherm is shown in Fig. 9.

The simulated 'order-order' relaxation isotherms fitted weighted

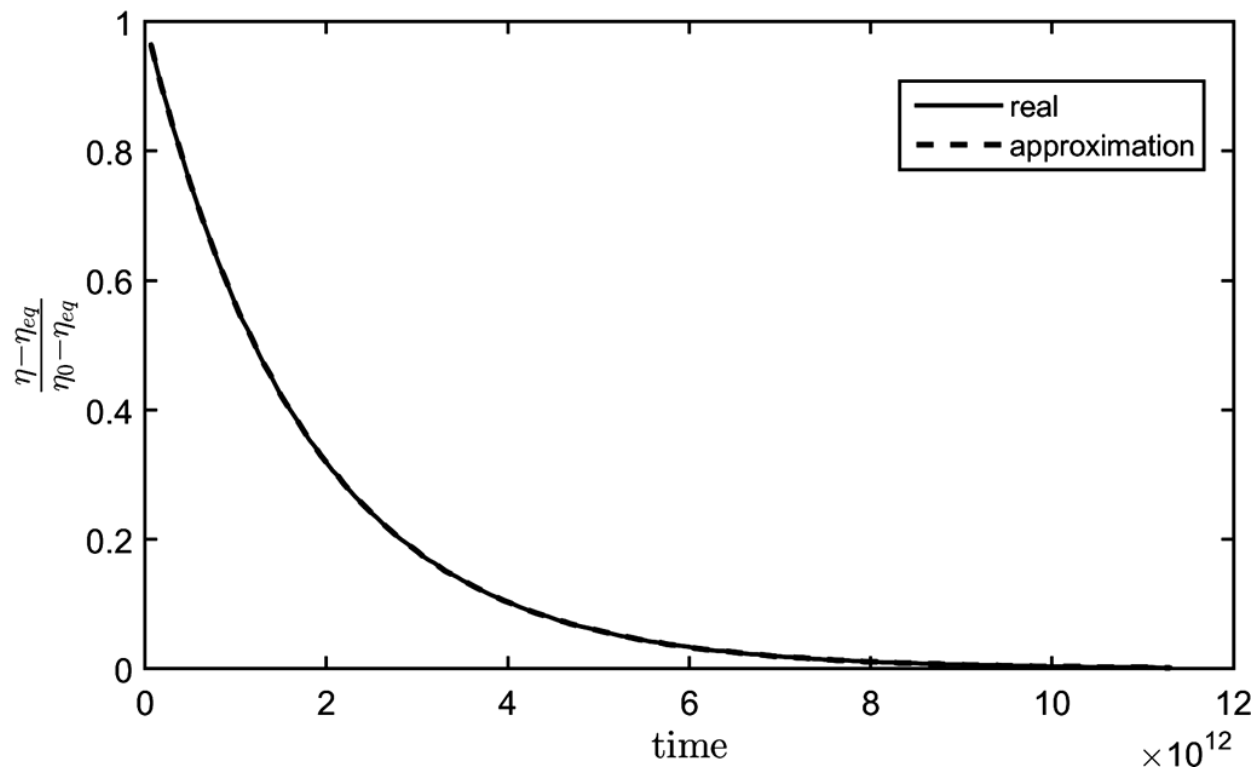

Fig. 9. 'Order-order' relaxation isotherm of the $A_{3} B\left(\mathrm{Ni}_{3} \mathrm{Al}\right)$ binary simulated at $T=800 \mathrm{~K}$ with the vacancy mechanism for the atomic migration. 
sums of two exponentials:

$$
\frac{\eta(t)-\eta(\infty)}{1-\eta(\infty)}=\left(1-A_{2}\right) \exp \left(-\frac{t}{\tau_{1}}\right)+A_{2} \exp \left(-\frac{t}{\tau_{2}}\right) .
$$

Qualitatively this result coincides with the findings of Kozubski and Oramus [23] obtained with Monte Carlo simulations. For example, at $T=800 \mathrm{~K}$, the amplitude $A_{2}$ of the equals about 0.03 , and relaxation time $\tau_{2}$ is almost two times shorter than $\tau_{1}: \tau_{2} / \tau_{1} \approx 0.54$. Both relaxation times $\tau_{1}$ and $\tau_{2}$ fulfil the Arrhenius laws (Fig. 10).

The consistency of the approach requires that the activation energies for both modes of the 'order-order' relaxation are identified with the slopes of the Arrhenius plots in Fig. 10 corrected with the increment $\Delta E^{\text {saddle }}$ (Eq. 58). The procedure results in

$$
Q_{1}^{\text {ordering }} \approx 5.33 \cdot 10^{-19} \mathrm{~J}, Q_{2}^{\text {ordering }} \approx 5.36 \cdot 10^{-19} \mathrm{~J} .
$$

Similarly, as in the case of simulations implemented with the exchange mechanism of atomic migration, the thermodynamic activation energies for the 'order-order' relaxations resulted close to the thermodynamic activation energy for the minority $B$-tracer diffu-

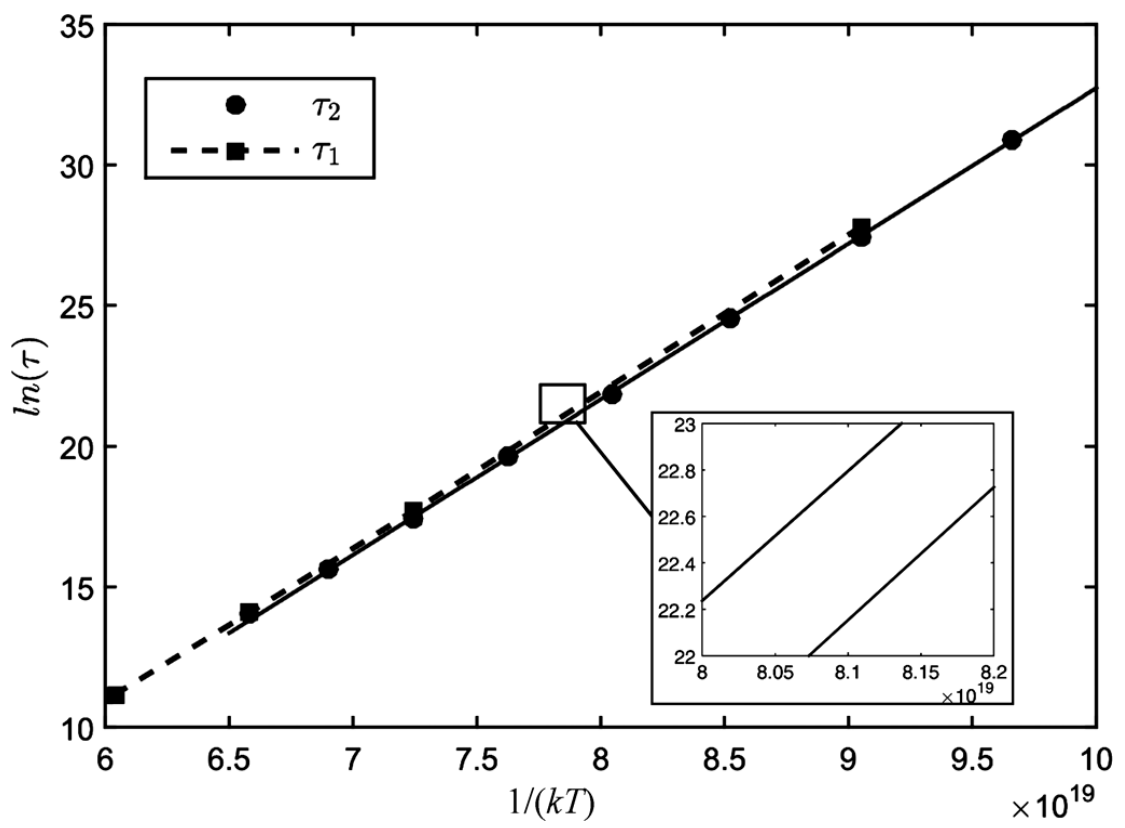

Fig. 10. Arrhenius plot of the relaxation times $\tau_{1}$ and $\tau_{2}$ of the 'orderorder' kinetics in $A_{3} B\left(\mathrm{Ni}_{3} \mathrm{Al}\right)$ evaluated with the vacancy mechanism of atomic migration. 
sion. It means, therefore, that the bottleneck of ordering is the migration of the minority component.

\section{KMF-SIMULATION RESULTS FOR THE BINARY SYSTEM WITH $L 1_{0}$-TYPE STRUCTURE}

The KMF simulations were also applied for the modelling of chemical (atomic) ordering phenomena in the FePt intermetallic compound. The compound orders in the f.c.c.-based $L 1_{0}$-type superstructure where alternating monatomic $\mathrm{Fe}$ and $\mathrm{Pt}$ planes may show three (100)-type orientations defining three variants of the superstructure. The superstructure generates very high magnetocrystalline anisotropy which, in turn, makes nanostructures of the system promising for the technology of high-density magnetic storage media. The free-standing nanolayers of the system have recently been extensively modelled by means of atomistic Monte Carlo simulations which revealed that the alternating $\mathrm{Fe}$ and $\mathrm{Pt}$ monatomic planes spontaneously take the orientation perpendicular to the (100) free surfaces limiting the layer [26, 27]. The process later observed also experimentally [29] nucleates on the surface and discontinuously advances inward the layer.

We used the nearest-neighbour pair interaction energies deduced from $a b$ initio calculations for FePt [29]: $V_{A A}=V_{\mathrm{FeFe}}=0.01145 \mathrm{eV}$, $V_{B B}=V_{\mathrm{PtPt}}=0.08563 \mathrm{eV}, V_{A A}=V_{\mathrm{FePt}}=-0.06705 \mathrm{eV}$. Because of the discontinuous character of the phenomenon, its modelling required application of the stochastic versions of $\operatorname{KMF}[9,10]$ since this version was specially designed to describe the ability of systems to overcome energetic barriers.

The present modelling of FePt layers initially ordered in the $L 1_{0}$ variant with monatomic planes parallel to (100)-oriented free surfaces yielded the following main results.

1. On the free surfaces built of Fe-atoms, the reorientation process spontaneously nucleated but its development stopped after having covered two crystalline planes (one row of f.c.c. unit cells) adjacent to the surface (Fig. 11). An initial noise was necessary to initiate such process on free surfaces built of Pt-atoms.

2. The reorientation front continued its propagation only if the amplitude of the stochastic noise of frequencies exceeded some threshold value (Fig. 12).

3 . In a free cubic nanoparticle, the reorientation process led to a complex mosaic of anti-phase domains of $L 1_{0}$ variants (Fig. 13).

The above results of the KMF (SKMF) modelling of the nanostructures FePt show that the method reproduces the Monte Carlo results and, therefore, is adequate to model ordering phenomena generating inhomogeneous superstructures. 
Moreover, simulation of the discontinuous process of the monatomic plane reorientation in FePt indicated the importance of the
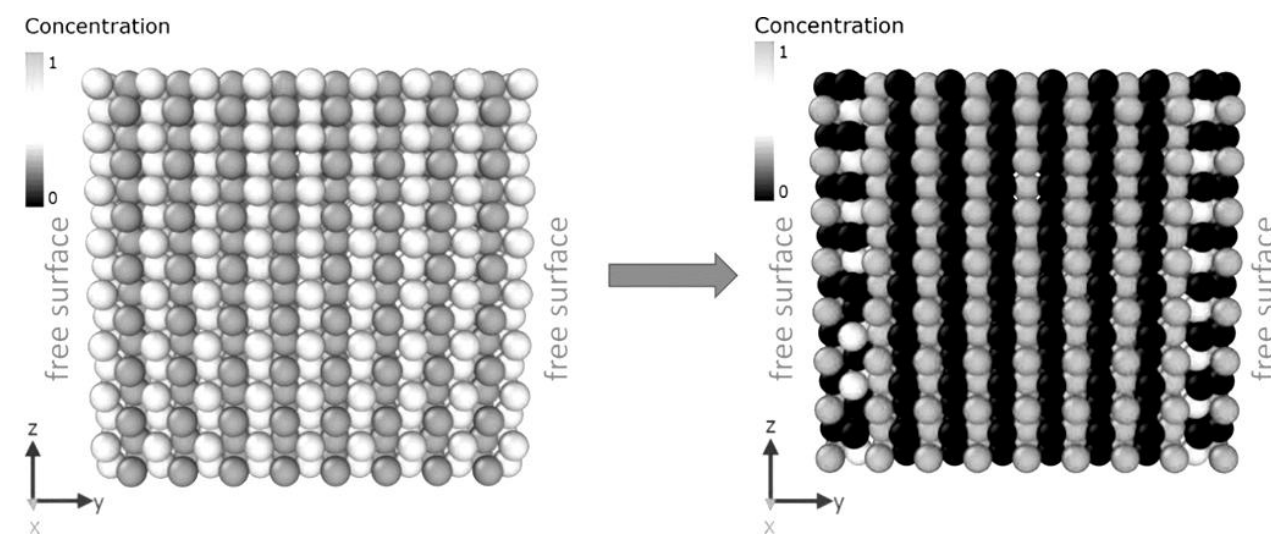

Fig. 11. Reorientation of the $\mathrm{Fe}$ and $\mathrm{Pt}$ monatomic planes in the $L 1_{0^{-}}$ ordered FePt layer initially limited by free iron surfaces.

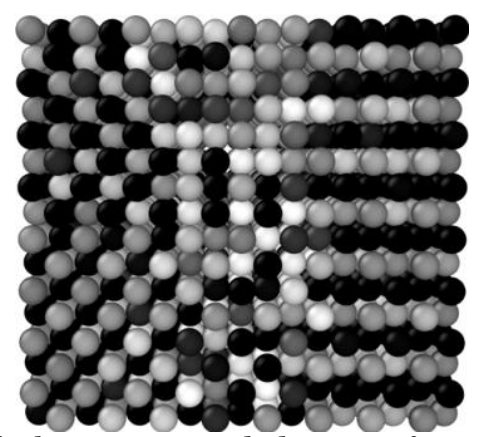

Fig. 12. Propagation of the reoriented domain from the free surface when the amplitude of dynamic noise $A$ is equal to 0.02 (in dimensionless units).

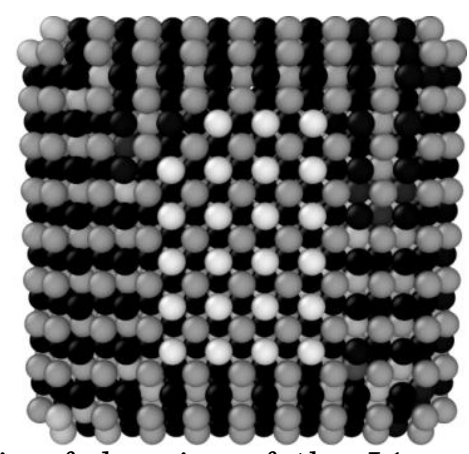

Fig. 13. Complex mosaic of domains of the $L 1_{0}$ variants in a cubic nanoparticle of FePt initially homogeneously ordered in one $L 1_{0}$ variant. 
implementation of the stochastic noise, without which the phenomenon neither nucleated nor advanced.

\section{DISCUSSION AND CONCLUSIONS}

Tracer diffusion and chemical ordering processes in two f.c.c. binary systems mimicking $\mathrm{Ni}_{3} \mathrm{Al}$ and $\mathrm{FePt}$ were simulated by means of the kinetic mean field method. Some of the results were compared with the ones previously obtained by simulating the same systems with atomistic Monte Carlo algorithms.

Kinetic equations formulated within the KMF technique, as originally proposed by G. Martin in 1990 [4], describe time evolution of configuration parameters which having a local character are, however, averaged over macroscopic parts of the system (crystallographic planes, sublattices, etc.). Moreover, none of the known realizations of the KMF method goes beyond the point approximation, i.e., the atomic configurations are parameterized by average site concentrations. In this way, any correlation effects are definitely beyond the current version of the method.

The systems simulated within the present work were modelled with fixed nearest-neighbour pair-interaction parameters fitted to their equilibrium properties and also fixed saddle-point energy whose value might also be fitted to the parameters of diffusion and ordering kinetics. Time evolution of the system configuration due to atomic migration was considered in two levels of approximation: (i) by assuming a simple, but non-physical 'direct exchange' mechanism and (ii) by approaching the reality and implementing the model with the vacancy mechanism.

$\mathrm{KMF}$ is a timesaving method, more efficient than kinetic Monte Carlo one. However, one should pay for everything! For the effectiveness, we pay by neglecting the correlation factors and, in general, time correlations for the atomic migration. As mentioned above, kinetic mean-field models cannot pretend on predicting the pre-exponential factors of tracer diffusion and ordering kinetics. It is evident for the direct exchange mechanism since it is not realistic mechanism. Moreover, this is true even for the vacancy mechanism because mean-field approach excludes 'memory' about past atomvacancy exchanges. Therefore, in all our studies, we concentrated on comparison of activation energies. Luckily, as demonstrated in this paper, all qualitative results of KMF correlate with known kinetic KMC results, at least for the f.c.c. alloys considered in this paper.

In view of all the approximations described above, only relative values of the evaluated parameters and the qualitative agreement with experimental results might be considered as significant. 
Indeed, the modelling of the $\mathrm{Ni}$ - and $\mathrm{Al}$-tracer diffusion in $\mathrm{Ni}_{3} \mathrm{Al}$ yielded higher diffusivity of $\mathrm{Ni}$ - the effect anticipated in most of the related investigations due to easy intrasublattice diffusion channel for the $\mathrm{Ni}$ atoms in the $L 1_{2}$-type superstructure of $\mathrm{Ni}_{3} \mathrm{Al}$. In contrary to the experimental investigations suffering from a lack of practically applicable $\mathrm{Al}^{*}$ tracers, the simulations made it possible to model the process directly. In addition, the higher thermodynamic activation energy for the $\mathrm{Al}^{*}$-tracer diffusion and its value close to the simulated thermodynamic activation energy for the 'order-order' kinetics in the same system is in agreement with the experimental results concerning 'order-order' kinetics and tracer diffusion of admixtures substituting for the $\mathrm{Al}$ atoms in $\mathrm{Ni}_{3} \mathrm{Al}$ (see, e.g., [3]).

It is interesting that the simulated 'order-order' relaxations in $\mathrm{Ni}_{3} \mathrm{Al}$ showed either one, or two-time scales depending on whether the 'direct exchange' or vacancy mechanism for the atomic migration was implemented. The presence of the two-time scales might recall the results obtained for the $\mathrm{Ni}_{3} \mathrm{Al}$ by means of atomistic Monte Carlo simulation [22]. It is supposed, however, that as the effect reported in Ref. [22] originated from a specific correlation of the atomic jumps (beyond the scope of the KMF formalism), the short time scale revealed by the present KMF simulations stems rather from the initial vacancy redistribution in the system.

The results obtained for the $L 1_{0}$-ordered $\mathrm{FePt}$ binary are of special interest. As followed from the atomistic Monte Carlo simulations [27], the process of the surface-induced re-orientation of the $\mathrm{Fe}$ and $\mathrm{Pt}$ monatomic planes shows a definitely discontinuous character. In addition, its nucleation requires that the system passes beyond some energetic barrier. Modelling of the phenomenon was, therefore, a good test for the stochastic variant of the KMF [9], [10]. The fact that implementation of the stochastic noise was necessary to reproduce the monatomic plane re-orientation process by $\mathrm{KMF}$ indicates the correctness of the method.

The KMF and SKMF methods, whose usefulness was indicated by the results obtained within the present work, is now developed in several directions. One of them is an extension of the mean-field parameterization upon the point approximation that will make it possible to apply the KMF (SKMF) to model much wider range of structural transformations in materials.

\section{ACKNOWLEDGEMENTS}

This work was supported by: the Marie Curie International Research Staff Exchange Scheme Fellowship IRSES within the 7th European Community Framework Programme under Grant 612552; 
Ministry of Education and Science of Ukraine under Grant 0115 U 000638 and Grant 0116 U 004691.

\section{REFERENCES}

1. K. Binder, Monte Carlo Methods in Statistical Physics (Berlin-Heidelberg: Springer: 1986).

2. Diffusion in Crystalline Solids (Eds. G. E. Murch and A. S. Nowick) (Orlando-New York: Academic Press: 2012).

3. R. Kozubski, Progress in Materials Science, 41, Nos. 1-2: 1 (1997).

4. G. Martin, Phys. Rev. B, 41, No. 4: 2279 (1990).

5. Z. Erdélyi, I. A. Szaby, and D. L. Beke, Phys. Rev. Lett., 89, No. 16: 165901 (2002).

6. Z. Erdélyi, M. Sladecek, L. M. Stadler, I. Zizak, G. A. Langer, M. Kis-Varga, and B. Sepiol, Science, 306, No.5703: 1913 (2004).

7. Z. Erdélyi, G. L. Katona, and D. L. Beke, Phys. Rev. B, 69, No. 11: 113407 (2004).

8. Z. Erdélyi, D. L. Beke, and A. Taranovskyy, Appl. Phys. Lett., 92, No. 13: 133110 (2008).

9. N. V. Storozhuk, K. V. Sopiga, and A. M. Gusak, Phil. Mag., 93, No. 16: 1999 (2013).

10. Z. Erdélyi, M. Pasichnyy, V. Bezpalchuk, J. J. Tomán, B. Gajdics, and A. M. Gusak, Computer Physics Communications, 204: 31 (2016).

11. J. M. Sanchez and D. De Fontaine, Phys. Rev. B, 25, No. 3: 1759 (1982).

12. A. G. Khachaturyan, Theory of Structural Transformations in Solids (Mineola, N.Y.: Dover Publications: 2008).

13. L. Q. Chen and A. G. Khachaturyan, Phys. Rev. B, 46, No. 10: 5899 (1992).

14. Y. Wang, D. Banerjee, C. C. Su, and A. G. Khachaturyan, Acta Materialia, 46, No. 9: 2983 (1998).

15. G. Inden and W. Pitsch, Materials Science and Technology. A Comprehensive Treatment (Eds. R. W. Cahn, P. Hansen, and E. J. Kramer) (Weinheim: VCH: 1991).

16. I. B. Borovsky, K. P. Gurov, I. D. Marchukova, and Yu. Eh. Ugaste, The Interdiffusion Processes in Alloys (Moscow: Nauka: 1973) (in Russian).

17. A. Biborski, R. Kozubski, and V. Pierron-Bohnes, Diffusion Foundations, 2: 191 (2014).

18. N. Bogoliubov, The Dynamical Theory in Statistical Physics (Delhi: Hindustan Pub. Corp.: 1965).

19. K. P. Gurov and A. M. Gusak, Fiz. Met. Metalloved., 59, No. 6: 1062 (1985) (in Russian).

20. O. M. Rymar and A. M. Gusak, Cherkasy University Bulletin: Physical and Mathematical Sciences, 349, No. 16: 50 (2015) (in Ukrainian).

21. V. M. Bezpalchuk and A. M. Gusak, Metallofiz. Noveishie Tekhnol., 37, No. 12: 1583 (2015) (in Ukrainian).

22. V. M. Bezpalchuk, M. O. Pasichnyy, and A. M. Gusak, Metallofiz. Noveishie Tekhnol., 38, No. 9: 1135 (2016) (in Ukrainian).

23. P. Oramus, R. Kozubski, V. Pierron-Bohnes, M. C. Cadeville, and W. Pfeiler, Phys. Rev. B, 63, No. 17: 174109 (2001). 
24. S. T. Frank, U. Södervall, and C. Herzig, Physica Status Solidi B, 191, No. 1: 45 (1995).

25. S. Divinski, S. Frank, U. Södervall, and C. Herzig, Acta Materialia, 46, No. 12: 4369 (1998).

26. M. Kozłowski, R. Kozubski, and C. Goyhenex, Diffusion Foundations, 1: 3 (2014).

27. M. Kozłowski, R. Kozubski, C. Goyhenex, V. Pierron-Bohnes, M. Rennhofer, and S. Malinov, Intermetallics, 17, No. 11: 907 (2009).

28. M. Rennhofer, M. Kozlowski, B. Laenens, B. Sepiol, R. Kozubski, D. Smeets, and A. Vantomme, Intermetallics, 18, No. 11: 2069 (2010).

29. M. Kozłowski, R. Kozubski, V. Pierron-Bohnes, and W. Pfeiler, Computational Materials Science, 33, Nos. 1-3: 287 (2005). 